\title{
Towards a Taxonomy of Masculinities: Mapping Hegemonic and Alternative Masculine Practices in Shashi Deshpande's The Dark Holds No Terror and That Long Silence
}

\author{
Suraj Gunwant ${ }^{1} \&$ Rashmi Gaur $^{2}$ \\ ${ }^{1}$ Ph.D. candidate at the department of Humanities E Social Sciences, IIT Roorkee. \\ Email:suraj.15may@gmail.com \\ ${ }^{2}$ Professor of English and Cultural Studies at the department of Humanities E Social Sciences, IIT \\ Roorkee.
}

Received April 19, 2016; Revised July 04, 2016; Accepted July 15, 2016; Published August 18, 2016

\begin{abstract}
This paper reads two early novels of Shashi Deshpande and maps the ways in which traditional and new alternative masculinities find juxtaposition in the chosen texts. Although Shashi Deshpande is regularly posited as an author of progressive feminist politics, whose fictions present a subjugated femininity under the oppression of a unitary and oppressive masculinity; this reading, however, complicates this position by exploring diverse and contradictory embodiments of manhood in her works. In so doing, this study submits that the presence of supportive or caring masculinities militates against the popular notion of a singular, oppressive and homogenous masculinity and problematizes the notion of pervasive and universal patriarchy. However, these caring or testicular masculinities do not find much textual endorsement. On the contrary, it is the traditional/ patriarchal masculinities that retain their dominance, which allows us to expose the novels' unconscious support of the status quo.
\end{abstract}

Keywords: Shashi Deshpande, Masculinities, Gender

\section{Home and the Nation in Anglophone Fiction}

The Indian English Novel's unique preoccupation with the nation vis-à-vis its vernacular counterparts has been noted, disseminated, and reiterated by a number of scholars engaged in the readings of what can be called the Indian English postcolonial text. This finding finds description in such celebrated texts as Aijaz Ahmed's In Theory: Nations, Classes, Literatures (1992) where Ahmed juxtaposes the position of the modern vernacular literature that foregrounds "our class structures, our familial ideologies, our management of our bodies and sexualities, our idealisms, our silences" in contrast with the Anglophone Indian fiction which is far more concerned with 'nation' as its 'primary ideological problematic' (p.118). However, in spite of her effort to carve a coherent trajectory of the Anglophone fiction in consonance with Ahmed's argument, Priyamvada Gopal (2009) clears a space for what she believes to be the 'provisional' and 'partial categorization' of 'familial' or 'domestic fiction' (p.139). In the chapter titled 'Family Matters: Domesticity and

(c) AesthetixMS 2016. This Open Access article is published under a Creative Commons Attribution Non-Commercial 4.0 International License (http://creativecommons.org/licenses/by-nc/4.o/), which permits non-commercial re-use, distribution, and reproduction in any medium, provided the original work is properly cited. For citation use the DOI. For commercial re-use, please contact editor@rupkatha.com. 
Gender in the Novel', Gopal acknowledges the dominance of women writers in the domestic fiction and engages with authors such as Anita Desai, Attia Hossain, Shashi Deshpande, Manju Kapoor and others. Gopal's assessment of the Indian English novel allows us to make use of a ready-made category in which Shashi Deshpande can be situated for a new hermeneutics informed by the questions of masculinity as a gender identity.

\section{Plurality and Instability in Masculinity}

For decades now, the engagement with gender in the Western academia, particularly feminist theory, has led to a disavowal of conventional, nature-based knowledge on gender and has problematized commonsensical formulations of discrete gender identity arising from sexual organs or hormones and has posed it firmly within culture (Beauvoir 1951; Greer 1971; Butler 1990). While such a system of thought has in itself become an orthodoxy when it pertains to its focus on women and femininity; a new wave of knowledge production under the intellectual shadow of academic feminist discourse has emerged in recent decades which has put men and masculinities in sharp focus and by so doing, has marked the hitherto overlooked category of masculinity as an object of intellectual endeavor (Carrigan, Connell, and Lee 1985; Hearn 1987, 1992; Kimmel 1988; Connell 1995; Petersen 1998). Not only does this extend the theorization of men's power over women in the tradition of second-wave feminism, there are also expositions of the powerlessness and instabilities underlying the solid and stable exterior of manhood (Goldberg 1976; Farrell 1993; Petersen 1998; Reeser 2010). For instance, Reeser (2010) affirms that studies concerning masculinities which emphasize "cross-cultural or cross-temporal differences make us aware of masculinity as particularly relative, since we come to see that what is taken for granted is not at all a given, but a fabrication or a construct of a given historical and cultural context" (p.2). As variations and differences across spatio-temporal spectrum consolidate the notion of a fractured gendered identity for men, it remains important to emphasize the role of culture in the creation of an artificial unitary and normative masculinity through discursive practices. Admittedly, there are differences across cultures, however, as David Gilmore (1990) has pointed out in his cross cultural anthropological study, most cultures "espouse a doctrine of a manhood-of-achievement" (p.221), even though there are exceptions of relaxation and passivity in men in certain cultures. The ideology of manhood constructs the hegemony of the discursively ubiquitous though not universal 'Man-the-Impregnator-Protector-Provider', and cultures accomplish such goals through repressive and ideological apparatuses. The discourse of gender, hence, makes discrete sex-roles for anatomically different bodies and those bodies that succeed at playing to the script avoid being robbed of their gender identity. The slipperiness of gender identity, more specifically masculinity, ensures that this success is often short lived, because, as in the case of male bodies, one single diversion from the sex role or stereotype may lead to the loss of manhood. But as times change the cultural definitions of real manhood also shift.

\section{Modernity and the Politics of the Indian English Novel}

Our unique position in history, the phase of late modernity that we inhabit is marked by acceleration in the phasing out of old traditional values. The consequences of modernity, to borrow Anthony Giddens' phrase, are acting against the persistence of old ways of being, thereby putting the cultural milieu in a position of transition. In this context, patriarchy, the traditional way in which the social was organized in the pre-modern era, is being systematically undermined. This notion is confirmed by John MacInnes (1998) who asserts that "particularly over the last half 
century, substantial changes have taken place in the sexual division of labour...men have lost a great deal of their power over women...have started to realize that they too constitute a gender" (p.1). However, perhaps, it is important to emphasize McGuin's (1999) assertion that 'the coordinating role of capitalism' in the expansion of cultural modernity, i.e., modern principles of social contract and formal equality, and contextualize how in the 'Other' of the world, the thirdworld or the non-West, the traditional may still predominate because of weaker links with first world capitalism. In such a scenario, the literature of the third world, we hypothesize, will be a site where the traditional will be predominant; the unconventional may be present, though it must populate the margins. Therefore, the gender politics will have shades of subtle inbetweenness. As the prospect of modernity cannot completely wash away the ideological legacy of the patriarchalist pre-modern, the contemporary social framework remains in a state of transition. Therefore, we contend that the chosen literary texts must engage with this state of transition in the Indian social order which is moving toward egalitarianism to live up to the ethos of modernity and yet the ghosts of gender and other forms of social inequalities remain to be exorcized.

\section{A Note on the Typology of Masculine Practices}

Our reading of the author's novels is informed by the perspective of the presence of plurality of ways of being men which is why the word "masculinity" is often denoted in its plural, i.e., 'masculinities' (Connell 1995). Additionally, we sometime incorporate the very cultural though academically sidelined ways of classifying men into popular categories of the Alpha and the Beta male. These categories can be read in correspondence with the academically accepted subsets of masculinity: 'Hegemonic masculinity' and 'Alternative masculinity'. While we agree to the fact that the plurality of manhood goes beyond the numbers that we have limited it to in our endeavor (Petersen 1998; Reeser 2010); the endless play of difference in this gender signifying practice has to be, in our opinion, limited to a certain number, in this case the number 2 , so as to create a form of knowledge that is culturally accessible and generalizable. What we intend to do is to provide a limited taxonomy or rather apply an already established and popular way of categorizing male attitudes and behaviours on the presentation of masculinity in Deshpande's chosen texts while acknowledging the inherent reductionism of such an initiative. As for the interpretation of the used terms 'hegemonic' and 'non-hegemonic/ alternative' masculinities, we have sought the support of the sociology of masculinities which very firmly align the concept of hegemonic masculinity with modes of entitlement, privilege and dominance (Cheng 1999). It is that form of manhood which is usually posited as the ideal in all patriarchal cultures (Connell 1995). The privilege and prestige that hegemonic masculinity enjoys is established through a manufactured cultural consent and this ideal is proposed as the model form for other masculinities while also putting alternative masculinities in the position of subordination. As Carrigan et al. (1987) describe "the ability to impose a particular definition on other kinds of masculinity is part of what we mean by 'hegemony' (p.179). One of the other important features of hegemonic masculinity is that "it is heterosexual" (p.180). If masculinity is a homosocial enactment, as Kimmel (1994) describes, compulsory heterosexuality remains a key ingredient in the manufacturing of normative masculinity; homosexuality in men is often aligned with the idea of marginalization in the hierarchy (Connell 2005). In this paper we use the notion of alternative masculinities as characterized by the male characters inability to live upto the masculine ideal of social dominance through material success and their lack of privilege in terms of preferential treatment. Other patterns may include an alignment with egalitarian ethos or subtle pro-feminist leanings. 


\section{Playing to the Script: Husbands and Normative Masculinity}

Both of Deshpande's texts have an educated middle-class woman as their protagonists who are capable of reflecting upon a host of social issues in which gender remains a key theme. As Chakaldar (2006) describes, the author articulates the "middle-class Indian womanhood caught between the demands of tradition and modernity" (p.84). As a side note on her style, Deshpande's narratives go on to promise a realistic portrayal of social relations in India by firmly subscribing to the genre of social realism, which makes evident that the author is not proposing a radical politics which is sometimes associated with other genres or modes, mainly the postcolonial magical realism, the dominant tradition post Rushdie's arrival. Even though Saikat Majumdar (2013) sees the marginalization of authors such as Deshpande in both the transnational book market and critical practice rooting from these authors' allegiance to a "modernist aesthetics and the ethics of alterity" in the face of the dominant "Rushdie-Jameson tradition of postmodernist postcoloniality" (p. 3o); however, our position is more in congruence with Ben-Yishai (2015) for whom Deshpande's realism is the reason for her dismissal as a "middle-brow, unexciting writer" as realism is often viewed "as naïve, implausible, simple-minded, middlebrow, or politically dubious." (p.12). This digression on Deshpande's formal aspects allows us to expose the author's deliberate strategy to stand as a dispassionate observer; to maintain the distance between description and activism. Her diction remains natural, in the face of an overwhelming amount of linguistic pyrotechnics and riotous prose of Rushdie and his ilk. Deshpande's matter-of-fact tone is another area where she is distinguished from her postmodernist counterparts. Given her style, her domestic fiction engages with men and masculinities in a relational, incidental and descriptive rather than critical manner.

Coming back to the question of masculinity, it has been noted that the ability to commit violence, to dominate, to control (both the self and the 'other') as well as the drive for material success are some of the pre-requisites for climbing up the hierarchy of masculinity (Cheng, 1999, 298). Although when such an assessment or claim is made, the idea of generic masculinity takes on the characteristics that we here identify with just one brand of masculinity, keeping the plurality of masculinity in mind. Yet this one brand, usually the culturally desired mode finds expression both in its presence as well as its absence in the novels of Deshpande. It is usually the husbands that come to occupy the traits associated with hegemonic masculinity, while the protagonist and often the narrators' experiences with these husbands that impel the protagonist to reflect on her being, who then undertakes a journey of gaining consciousness and transforms into Sartre's being-for-itself from her earlier state of a being-in-itself. The flashbacks to a routine based consciousness devoid past becomes a method of analysis which is critical of the supposed order and happiness that a family of four is supposed to bring to the female protagonist. Both stories have in common a middle class secure existence and two children, a girl and a boy, a portrait of sorts of the ideal family exalted by detergent advertisements. Therefore a critical approach to it, the excavation of the unquiet land beneath the surface of a contrived reality foisted by a culture that insists on compulsory heterosexuality and successful marriage, becomes a way in which the unfolding of gendering of the sexed bodies takes place. Indeed, as one would notice, the narratives dramatize violence and disenchantment early on. For instance, The Dark Holds No Terror (DHNT) begins with the description of an act of sexual violence on the protagonist Saru by her husband Manohar and in That Long Silence (TLS) the narrator Jaya describes her experience of marital relationship with Mohan by using a proverb that brings to attention an uncanny similarity between the lack of freedom in the institution of marriage and the condition of two bullocks being yoked together. The institution of marriage is conceived of as captivity characterized by lack of autonomy or freedom, the husband being the other bullock, the 
'absolute' one, even a stronger one to whom the 'other' must capitulate. Mohan, who occupies a senior position in bureaucracy, has got himself into trouble by conniving with others in a case of fraudulence and this situation threatens his status as a secure middle class family patriarch. Obviously, the fraud has been committed for the maintenance of an upwardly mobile middleclass existence which allows the patriarch to enjoy admiration in a society which has imposed on him the job of the protector of 'his' woman and 'his' family from social and financial insecurities. The importance of social dominance in the construction of the manly ideal cannot be overlooked as success in material endeavours is the key to moving up the value chain, to become what is called the 'Alpha' male. Indeed, it was his ability to shoulder the financial responsibility of a future family signaled by his engineering job that made him eligible for Jaya's hands in the first place. "He seems a very decent chap, soft-spoken and quiet maybe, but determined, you know. He'll make his way, he's very independent. And he has a good job, as junior engineer in the new steel plant" (TLS, p.92). The threat of unemployment therefore becomes a possibility of loss of what Connell likes to call the 'patriarchal dividend'. The legacy of the patriarchal past ensures a major dent in the consolidation of masculine identity, a sort of 'crisis in masculinity' which Mohan has to negotiate in an atmosphere which puts a premium on his fitness as a provider. In this moment of deep crisis he blurts out what he feels to be the reality behind his wife's coldness: "the truth is that you despise me because I've failed. As long as I had my job and position, it was all right; as long as I could give you all the comforts, it was all right" (TLS, p. 121). Mohan is not alone in the collapse of the Alpha dream. Manohar in The Dark Holds No Terror (DHNT) appeared an Alpha in the making in his college days, his future being predicted by his own professor as someone who would reshape the contours of modern poetry. He was the 'Shelley' to the protagonist who dreamed of becoming his 'Harriet', her naiveté expressed in her ignorance of the fate of Harriet. Consider this: "He was the figure I fantasized about, the person round whom I wove my foolish dreams...always the age old feminine dream of a superior conquering male...it was like having a crush on a movie star. It was not part of real life" (p.53-54). These could very well be lines lifted from a romance novel sold on amazon for Rs. 199 with such a title as Wanted by the Alpha Billionaire in which the weak and poor heroine pines for submission toward a strong and flawless male significant other. Manohar is another failed figure given his low salary as a lecturer in a small private college unable to live up to the dream he inspired, the dwarfness compounded by the rising influence of his wife as a doctor. Therefore, the realization on the part of the narrator, Saru, of what Germaine Greer likes to call 'the middle class myth of love and marriage', an idea to which Greer has dedicated an entire chapter in her seminal The Female Eunuch (1971), takes place through Manu's failure at accumulating material success, his defeat in becoming the promised celebrity poet and his failure in providing a decent living to his wife. "Yet soon enough, I knew he was no Shelley. I knew also that it was I and not Manu who would get us out of the morass we were in" (p.91). This leads to a sexual wandering toward another appearingly Alpha who comes in the form of Boozie, but the recognition of his homosexuality turns him into a farcicial character as it is through his hyper-hetero-sexuality, his edginess in matters of sex to the point of predatoriness, that he had become the object of romantic interest. Of course, his position and his immense popularity as an accomplished surgeon also had a big role to play in the strengthening of his attractive persona because the female narrator finds in him the way out of financial difficulties. His description echoes the sketch of Manu: "Boozie, according to Saru, "came close to a woman's magazine hero...dark, rugged, handsome and masterful" (DHNT, p.88), but "they were all props, to help create and maintain the necessary image...it was part of his reputation, his fondness for pretty girls" (DHNT, p. 88). We learn later about his concealed natural sexual orientation toward his own sex and how his inflated sexuality, "his fondness for 
pretty girls" is artificially constructed and performed repeatedly to keep up the veneer of unquestionable heterosexuality which protects his manhood, his right to live respectfully as a man. Even though homosexuality is only one of the ways in which one is wired in terms of one's sexual orientation and it has no explicit connection with gender, yet male homosexuality and femininity are often conflated so much so that Michael Kimmel, the distinguished sociologist of masculinities, perceives masculinity as homophobia. In his celebrated article "Masculinity as Homophobia" Kimmel states that "homophobia is a central organizing principle of our cultural definition of manhood" (p. 131). The development of men's gender identity happens through active avoidance of anything remotely feminine or sissy. The fear of being perceived as effeminate which is usually conflated with homosexuality remains a pressing psychological issue for men. In other words, "homophobia, the fear of being perceived as gay, as not a real man, keeps men exaggerating all the traditional rules of masculinity, including sexual predation with women" (Kimmel, p.132). Boozie, therefore, brings forth the insecurity and fear male bodies negotiate with the culture that puts a premium on masculinity and that sees men as natural carriers of the ideology of manhood, in which any resistance or deviation is not acceptable and also how this phenomenon forces men to inflate qualities of aggression and hypersexuality in order to be socially acknowledged as proper men. Manohar, Mohan and Boozie therefore represent failed attempts at earning or rather retaining the badge of manhood and it establishes, in a literary way, the incompleteness of being masculine, that it is only a process of being and that one never becomes completely masculine, and that one single failure, deviation from the plastic hegemonic code could slip the facade away.

\section{Lovers and Dissenters: Alternative Masculinities}

The lovers in Deshpande's works follow a different trajectory of being and doing. Although, it is difficult to fully attribute the title 'lovers' to these male characters because the protagonists themselves do not see them as objects of romance even though at times the sexual tension with these characters is palpable. What is also interesting to note here is the mind-body dualism that female narrators express by withdrawing themselves from forming sexual liaisons with these outsiders even though their bodies may be open to such 'indiscretions'. Take, for instance, Jaya's take on her own mind-body divide: "There had been nothing but an overwhelming urge to respond to him with my body, the equally overwhelming certainty of my mind that I could not do so" (TLS, p. 157). In such instances, the Freudian superego wins over the unwise Id leading to conclude the overarching almost sovereign power of cultural morality over its subjects who resist yielding to passions and establish the superiority of reasoned actions, here it becomes marriage, over irrational transgressions of compulsory monogamy. The narratives map these digressions of Saru and Jaya in which male characters outside the immediate family play friends, philosophers and guides and the protagonists drift toward them even in the absence of a perfect nomenclature of these relationships. Kamat in That Long Silence and Padma in The Dark Holds No Terror, and if we could borrow Naren from Deshpande's first novel Roots and Shadows solidifies our classification of these other masculinities. The common pattern we witness in these characters is a resistance toward success oriented conventional heterosexual masculinity and therefore they can be apprehended as alternatives to the dominant ways of conceiving manhood. Take, for instance, Kamat about whose career and family we do not know; Kamat who does not hesitate to cook and share recipes with Jaya. Indeed, the protagonist, an educated woman appears considerably orthodox in her approach towards matters of the sexual division of labour when she acknowledges: "He hadn't seemed to mind being found doing something that was to me 
unmanly" (TLS, p.152). It is in fact important to note how patriarchal the protagonist herself is of a novel which is frequently dubbed as having feminist sensibility; also important is to take note of the bildungsroman tone of the novel where the protagonist appears to be the mouthpiece of the author's views. Coming back to Kamat, we do not see him being driven toward building a career for himself by fair or unfair means unlike Mohan who appeals to us like a modern middle-class avatar of Jay Gatsby of The Great Gatsby in his passion for material success even if it calls for unfair means and his preference for Jaya because she could bring to him upper-class culture through her English convent education and facility for writing fiction. On the contrary, Kamat sees Jaya as an individual with potential to carve a niche for herself even in the public sphere through her writings. He does not match the profile of the desirable man of romance novels or women's magazine as physically he is "greying, middle-aged and bulky" (TLS, p.156); he represents unconventional masculinity as he does not want to be Kimmel's "sturdy oak" or a husband who is "like a sheltering tree". Kamat is open to discussing sensitive, personal and emotional matters with Jaya who had been craving the same from her husband. She describes her feelings thus: "With this man I had not been a woman. I had been just myself- Jaya. There had been an ease in our relationship I had never known in any other. There had been nothing I could not say to him." (TLS, p.153). The use of her name in the aforementioned quotation is important as she distinguishes between Suhasini- the name given to her by Mohan, her husband- and Jaya, her real name. While reading the novel we are made aware of the meaning of 'Jaya' which stands for 'victory' but the meaning of 'Suhasini' is not explained, perhaps to keep implicit the notion of submission and compliance that must adorn a married woman. But Kamat reinstates the conception of Jaya by making her realize how her feeling of victimization "would drag [her] down into a soft, squishy bog of self-pity" (TLS, p.148) and this leads to the metaphorical annihilation of both 'Suhasini' and its creator, Mohan. "Later, there had been confusion. 'Jaya' he had said and I had become only Jaya. It had annihilated Mohan entirely" (TLS, p.157).

Padma in The Dark Holds No Terror is another outsider who does not subscribe to the dominant ideology of coercive masculinity. In opposition to Manohar who was very popular in college due to his vivacity and charm, his poetry being the expression of his creativity and culture, Padma is "poor Padma" because he is "always so tactless, so unerringly hitting on the wrong thing to say...he was the most unpopular student in the class" (DHNT, p.126). It turns out that not only was Padma an outcast, a Beta, due to his lack of social intelligence but that he had lacked that very thing which forms the basis of hegemonic masculinity; the author uses the phrase "a will to compete and succeed", clearly alluding to Nietzsche's will-to-power. Padma is described by a lack. If success could be read as the phallic signifier of hegemonic masculinity, then those described by a lack allegorically become "the male eunuchs", to borrow and play with Germaine Greer's phraseology. "He had always lacked something, a hardness maybe, or a will to compete and succeed" (DHNT, p.126). Such descriptions of non-hegemonic masculinities, which associate it with a lack reinforce and perpetuate gender inequality by keeping the high position of dominant, success-oriented masculinity intact. Padma, as opposed to Manohar, also does not expect his wife to restrict herself to perform conventional gendered wifely duties in the private sphere and is in fact visibly perturbed because his wife has internalized the very configurations which he himself has resisted, hence the anger: "My wife! She can't talk about anything but servants and the children. And prices. I earn enough, but she's perpetually trying to economize. She never has her food until I go home and have mine, she cooks just what I like, and she never calls me by my name" (DHNT, p.132). If the Alpha husbands demand the retention of clear gender boundaries and enforce hierarchy between the sexes as in the case of Manohar and Mohan, then the presence of Betas like Kamat and Padma militant against the notion of a unified patriarchal male attitude. 
Indeed, the concept of patriarchy has itself come under attack from many quarters because of its inability to register the complexity of gender interactions where often men have actively supported women in their liberation. Patriarchy conjures up the picture of an overarching bleak social determinism in which liberation and shifts in gender dynamics according to changing times are not often captured. Stephen Whitehead in his book Men and Masculinities (2002) draws our attention to this issue when he shares that "despite the emotive power of the term and its continued use in academia, patriarchy has been subject to increasing critique by feminists" (p.87). The remarks made by Haregraves (1982) can be reiterated here to add on to the emphasis: "the concept of patriarchy implies a fixed state of male oppression over women, rather than a fluid relationship between men and women which is complex and moves with great speed at times." (p.115). The fluidity that can take place in a man-woman relationship without the necessary insertion of oppression, something that often happens when critical reading happens around the concept of patriarchy, can be apprehended between Indu and Naren from Deshpande's Roots and Shadows (R\&S) who recall the reader of Jaya and Kamat from That Long Silence. Naren's inability to situate himself within the socially desirable code of traditional breadwinner masculinity can be used to align with Kamat who appears almost his character descendent. He is fickle, irresponsible and unemployed because of which Mini does not want to marry him. She says that he "is never serious and is joking about everything" (R\&S, p.88). Where Indu is submitting to the social mores yet is drawn to him, Naren revolts or rebels against the norms placed in conjunction with conventional masculinity; he quits his job and lives the life of a bright yet unaccomplished nonconformist. However, we see that non-conformist male characters such as Kamat and Naren also pay the price of being mavericks in a social order which demands submission. We see that in the suicides that both Kamat and Naren commit in the absence of any evident reason and also in the almost sudden disappearance of Padma. The texts do not contextualize the death/ disappearance of these important characters, their erasure becomes an act of reinstatement of the conventional hegemonic order. Towards the end of these novels, we witness the protagonists retreating from stepping toward a new liberated beginning, and their decision to go back to their respective husbands signals the reactionary patriarchal leaning of the texts.

\section{Conclusion}

In conclusion, Shashi Deshpande's texts offer a complicated reading of contemporary Indian masculinity; they contest the notion of a self-evident singular oppressive masculinity by foregrounding the neglected though important dimension of alternatives to normative masculine practices. The novels are a rich site to map not only the ways in which normative or hegemonic forms of masculinities are constructed by the texts, but also the methods the texts adopt in order to propose these models as aspirational to the reader. While it is true that these stories are woven around middle-class women's experience of subjugation in and around oppressive masculinities represented often by the husbands and are politically leaned toward conservatism in the process of upholding traditional masculinities toward the end of the narratives; yet the simple inclusion or presence of non-oppressive masculinities, embodied by Kamat, Padma and Naren alerts us to the transitional nature of patriarchy. Patriarchy then appears not as an eternal or fixed system; the very arrival of alternative masculinities in these texts signals a change in the social world which these narratives have attempted to chronicle. 


\section{References}

Ahmad, Aijaz. (1992). In Theory: Classes, Nations, Literatures . London: Verso.

Ben-Yishai, A. (2015). "By its very presence": Conventionality and commonality in Shashi Deshpande's realism. The Journal of Commonwealth Literature.

Butler, Judith. (2006). Gender Trouble: Feminism and the Subversion of Identity. Routledge.

Carrigan, T., Connell, B. and Lee, J. (1985) 'Toward a new sociology of masculinity', Theory and Society, 14(5), pp. 551-604.

Chakladar, A. (2006). Of Houses and Canons : Reading the Novels of Shashi Deshpande. ARIEL, 37(1), 81-97.

Cheng, C. (1999). Marginalized Masculinites and Hegemonic Masculinity: An Introduction. The Journal of Men's Studies, 7(3), 295-313.

Connell, R.W. (1995) Masculinities. Cambridge: Polity Press in association with Blackwell Publishers.

Deshpande, Shashi. (200o). The Dark Holds No Terror . New Delhi: Penguin. . (2008). That Long Silence. New Delhi: Penguin India. (2012). Roots and Shadows. New Delhi: Orient Blackswan.

Farrell, W. (1993). The myth of male power: Why men are the disposable sex. Simon \& Schuster.

Giddens, Anthony. (1990). The Consequences of Modernity. Stanford, CA: Stanford UP.

Gilmore, D. D. (1990). Manhood in the making: Cultural concepts of masculinity. New Haven, CT: Yale University Press.

Gopal, Priyamvada. (2009). The Indian English Novel: Nation, History, and Narration . Oxford: Oxford UP.

Greer, G. (1970) The female eunuch. London: HarperCollins Distribution Services.

Hargreaves, J. (1982). Sport, culture, and ideology. London: Routledge \& Kegan Paul.

Hearn, J. (1987) Sex at work: The power and paradox of organisation sexuality. Brighton: Prentice Hall/Harvester Wheatsheaf.

Hearn, J. (1992) Men in the public eye: The construction and Deconstruction of public men and public Patriarchies. United Kingdom: Taylor \& Francis.

Kimmel, M.S. (1988) Changing men: New directions in research on men and masculinity. 5th edn. United States: Sage Publications.

-----. (2004). Masculinity as homophobia: Fear, shame, and silence in the construction of gender identity. In Brod, H. \& Kaufman, M. (eds.), Theorizing masculinities (119-141). Thousand Oaks, CA: Sage Publications (CA).

MacInnes, J. (1998). The end of masculinity: The confusion of sexual genesis and sexual difference in modern society. Buckingham: Open University Press.

Majumdar, S. (2013). Prose of the world: Modernism and the banality of empire. New York: Columbia University Press.

McGuigan, Jim. (1999). Modernity and postmodern Culture. Buckingham: Open UP.

Parshley, H.M. and de Beauvoir, S. (1953) The second sex. New York: Alfred A. Knopf.

Petersen, A.R. (1998) Unmasking the masculine: 'Men' and 'identity' in a sceptical age. Thousand Oaks, CA: Sage Publications.

Reeser, T.W. (2010) Masculinities in theory: An introduction. Malden, MA: Wiley-Blackwell

Whitehead, S. (2002). Men and masculinities: Key themes and new directions. Cambridge: Polity Press. 